\title{
Effects of Temperature on Enantiomerization Energy and Distribution of Isomers in the Chiral $\mathrm{Cu}_{13}$ Cluster
}

\author{
Cesar Castillo-Quevedo ${ }^{1}$, Carlos Emiliano Buelna-Garcia ${ }^{2,3}$, Edgar Paredes-Sotelo ${ }^{2}$, Eduardo Robles-Chaparro ${ }^{4}$, \\ Edgar Zamora-Gonzalez ${ }^{5}$, Martha Fabiola Martin-del-Campo-Solis ${ }^{1}$, Jesus Manuel Quiroz-Castillo ${ }^{2}$, \\ Teresa del-Castillo-Castro ${ }^{2}$ D , Gerardo Martínez-Guajardo ${ }^{6}$, Aned de-Leon-Flores ${ }^{4}$, Manuel Cortez-Valadez ${ }^{7}$, \\ Filiberto Ortiz-Chi ${ }^{8}$, Tulio Gaxiola ${ }^{9}$, Santos Jesus Castillo ${ }^{7}$, Alejandro Vásquez-Espinal ${ }^{10} \mathbb{D}^{\mathbb{D}}, \mathrm{Sudip}^{\mathrm{Pan}}{ }^{11}$ and \\ Jose Luis Cabellos ${ }^{7, *}$
}

1 Departamento de Fundamentos del Conocimiento, Centro Universitario del Norte, Universidad de Guadalajara, Carretera Federal No. 23, Km. 191, C.P., Colotlán 46200, Jalisco, Mexico; castillo.quevedo@cunorte.udg.mx (C.C.-Q.); mfmartindelcampo@cunorte.udg.mx (M.F.M.-d.-C.-S.)

2 Departamento de Investigación en Polímeros y Materiales, Edificio 3G, Universidad de Sonora, Hermosillo 83000, Sonora, Mexico; a209205768@unison.mx (C.E.B.-G.); a213216667@unison.mx (E.P.-S.);

check for

updates

Citation: Castillo-Quevedo, C.; Buelna-Garcia, C.E.; Paredes-Sotelo, E.; Robles-Chaparro, E.;

Zamora-Gonzalez, E.;

Martin-del-Campo-Solis, M.F.;

Quiroz-Castillo, J.M.;

del-Castillo-Castro, T.;

Martínez-Guajardo, G.;

de-Leon-Flores, A.; et al. Effects of

Temperature on Enantiomerization

Energy and Distribution of Isomers in the Chiral $\mathrm{Cu}_{13}$ Cluster. Molecules 2021, 26, 5710. https://doi.org/ $10.3390 /$ molecules 26185710

Academic Editors: Guankui Long,

Giuseppe Cirillo and Hom

Nath Dhakal

Received: 25 July 2021

Accepted: 17 September 2021

Published: 21 September 2021

Publisher's Note: MDPI stays neutral with regard to jurisdictional claims in published maps and institutional affiliations.

Copyright: (c) 2021 by the authors. Licensee MDPI, Basel, Switzerland. This article is an open access article distributed under the terms and conditions of the Creative Commons Attribution (CC BY) license (https:// creativecommons.org/licenses/by/ $4.0 /)$. jesus.quiroz@unison.mx (J.M.Q.-C.); teresa.delcastillo@unison.mx (T.d.-C.-C.)

3 Organización Científica y Tecnológica del Desierto, Hermosillo 83150, Sonora, Mexico

4 Departamento de Ciencias Químico Biologicas, Edificio 5A, Universidad de Sonora, Hermosillo 83000, Sonora, Mexico; a214201767@unison.mx (E.R.-C.); aned.deleon@unison.mx (A.d.-L.-F.)

5 Departamento de Bienestar y Desarrollo Sustentable, Centro Universitario del Norte, Universidad de Guadalajara, Carretera Federal No. 23, Km. 191, C.P., Colotlán 46200, Jalisco, Mexico; edgar.zamora@cunorte.udg.mx

6 Unidad Académica de Ciencias Químicas, Área de Ciencias de la Salud, Universidad Autónomade Zacatecas, Km. 6 Carretera Zacatecas-Guadalajara s/n, Ejido La Escondida C.P., Zacatecas 98160, Zac, Mexico; germtzguajardo@uaz.edu.mx

7 Departamento de Investigación en Física, Edificio 3M, Universidad de Sonora, Hermosillo 83000, Sonora, Mexico; jose.cortez@unison.mx (M.C.-V.); santos.castillo@unison.mx (S.J.C.)

8 CONACYT-Universidad Juárez Autónoma de Tabasco, Centro de Investigación de Ciencia y Tecnología Aplicada de Tabasco, Cunduacán 86690, Tabasco, Mexico; fortiz@conacyt.mx

9 Facultad de Ciencias Físico-Matemáticas de la Universidad Autónoma de Sinaloa, Culiacán 80010, Sinaloa, Mexico; tuliogax@uas.edu.mx

10 Computational and Theoretical Chemistry Group Departamento de Ciencias Químicas, Facultad de Ciencias Exactas, Universidad Andres Bello, Republica 498, Santiago 8370035, Chile; a.vasquezespinal@uandresbello.edu

11 Fachbereich Chemie, Philipps-Universität Marburg, Hans-Meerwein-Straße 4, 35032 Marburg, Germany; pans@chemie.uni-marburg.de

* Correspondence: jose.cabellos@unison.mx

Abstract: In this study, we report the lowest energy structure of bare $\mathrm{Cu}_{13}$ nanoclusters as a pair of enantiomers at room temperature. Moreover, we compute the enantiomerization energy for the interconversion from minus to plus structures in the chiral putative global minimum for temperatures ranging from 20 to $1300 \mathrm{~K}$. Additionally, employing nanothermodynamics, we compute the probabilities of occurrence for each particular isomer as a function of temperature. To achieve that, we explore the free energy surface of the $\mathrm{Cu}_{13}$ cluster, employing a genetic algorithm coupled with density functional theory. Moreover, we discuss the energetic ordering of isomers computed with various density functionals. Based on the computed thermal population, our results show that the chiral putative global minimum strongly dominates at room temperature.

Keywords: nanothermodynamics; thermal population; chirality; DFT; first-principles calculations; electronic structure; $\mathrm{Cu}_{13}$ nanoclusters; genetic algorithm; probabilities; enantiomerization energy

\section{Introduction}

Transition-metal (TM) nanoclusters have been widely studied due to their potential applications in catalysis [1-3], photoluminescence [4], photonics [5], magnetism [4], chi- 
rality [6], and the design of new materials $[7,8] . \mathrm{Cu}$ is a $3 \mathrm{~d}$ TM with several oxidation states $[9,10]$, which explains its reactivity and confers many interesting physical and chemical properties $[9,10]$. Moreover, the high boiling point of $\mathrm{Cu}$ makes it compatible with high-temperature chemical reactions. Clusters are aggregates of atoms at the nanoscale size, which exhibit unusual physicochemical properties [11]. Cu clusters are particularly fascinating due to their applications in catalysis [10], light-emitting devices [12], and nanotechnology [13], despite presenting challenges such as their easy oxidation [13]. The most stable structure of small $\mathrm{Cu}$ clusters has been investigated by density functional theory (DFT) studies [14-17] and considering the Jahn-Teller effect [18]. In the early 2000s, Poater et al. [19] characterized neutral copper clusters $\left(\mathrm{Cu}_{n} n=1-9\right)$ using computed chemical reactivity descriptors within the DFT framework. Later, atomic structures and reactivity descriptors of $\mathrm{Cu}_{n} \mathrm{CO}(n=1,9)$ were computed and discussed [19]. Calaminici et al. reported the structure of neutral and anionic $\mathrm{Cu}_{9}$ clusters, employing DFT [20]. Moreover, in previous combined theoretical-experimental studies, the computed removal energies were compared with the measured photoelectron spectra in anionic $\mathrm{Cu}_{n}(n=9,20)$ clusters [21], and later, the optical absorption of small $\mathrm{Cu}$ clusters was presented [22]. Based on their geometry and electronic structure, atomic clusters could be characterized by magic numbers [1,23-25] that form highly symmetric structures, for example, icosahedron (ICO) and cuboctahedron (CUB) shapes [1]. From the geometrical point of view, the first magic number that appears is 13. Experimental studies have found magic $\mathrm{TM}_{13}$ clusters for $\mathrm{Fe}$ and Ti, amongst others $[1,26]$. Previous theoretical studies based on the empirical potential showed that the lowest energy structures of $\mathrm{Cu}_{13}$ clusters were the icosahedron and the cuboctahedron [27]; those structures consist of a central atom surrounded by $12 \mathrm{Cu}$ atoms. In contrast, Guvelioglu et al. [28], within the framework of DFT, found that the lowest energy structure of $\mathrm{Cu}_{13}$ is the double-layered structure, and in the same year, Itoh et al. [29] reported a similar double-layer structure as the putative global minimum. Yang et al. [30] explored the structural evolution of $\mathrm{Cu}_{n}(n=8-20)$ anions and found platelike structures. Later, larger $\mathrm{Cu}_{n}(n=20-30)$ clusters were investigated, and it was found that the structures are based on a 13-atom icosahedral core [31]. In previous studies, $\mathrm{Cu}_{13}$ was investigated because it was found to have an icosahedral structure that has a high percentage of edge and corner sites and high-index facets, resulting in increased catalytic activities [32-35]. In most cases, low-energy $\mathrm{Cu}$ clusters have preferentially lower symmetry structures [36], although some present distorted structures [36,37]. Although there are many studies on $\mathrm{Cu}$ clusters, the chirality of $\mathrm{Cu}_{13}$ clusters has not been discussed. In general, chirality plays a decisive role in biological activity and life processes [38]. Remarkably, chiral nanoclusters have attracted attention because they have applications in chiral materials with novel properties $[39,40]$. Previous theoretical studies on PtPd co-doped silicon clusters reported chiral and fluxional low-energy structures [41]. Recently, Kong et al. [42] reported propeller-like chiral AIE copper (I) clusters with exciting properties. However, clusters' properties depend on their putative global minimum and low-energy structures, considering achiral and chiral structures. Hence, we need to know the distributions of isomers at different temperatures [43]. The lowest- and low-energy geometries, composition, and temperature [43-45] of the ensemble determine all the properties of a cluster at temperature T, i.e., its electronic, structural, vibrational, and optical properties, as well as its chemical reactivity. Moreover, the atomic structure is the first level at which it is possible to manipulate the macroscopic properties of a cluster [1].

In this study, intending to elucidate the lowest- and the low-energy structures of neutral $\mathrm{Cu}_{13}$ clusters at temperature $\mathrm{T}$, we explored their free energy surface by employing a genetic algorithm coupled to DFT. We computed the probability of occurrence of each particular isomer, employing nanothermodynamics for temperatures ranging from 20 to $1500 \mathrm{~K}$. Our findings show that the putative global minimum is a chiral structure at room temperature. Moreover, we computed the transition state (TS), i.e., the enantiomerization energy for temperatures ranging from 20 to $1300 \mathrm{~K}$, for interconversion of a pair of enantiomers (Plus, $\mathrm{P}$, and Minus, M). Our computations showed that enantiomerization 
barriers led to persistently chiral structures and enabled the complete separation of enantiomers at room temperature [46,47]. The remainder of the manuscript is organized as follows. Section 2 provides the computational details and a brief overview of the theory and the algorithms used. The results and discussion are presented in Section 3. We discuss the low-energy structures, the effect of the DFT functionals on the energetic ordering of isomers, and the origin of the slight $0.41 \mathrm{kcal} / \mathrm{mol}$ energy differences. We analyze the interconversion energy barrier between $\mathrm{P}$ and $\mathrm{M}$ enantiomers, the effects of the temperature in the energy barriers, and the thermal population. Conclusions are given in Section 4.

\section{Theoretical Methods and Computational Details}

All geometrical structures were optimized locally without imposing any symmetry; the self-consistent field procedure was performed with a convergence criterion of $10^{-6}$ a.u. energy, maximum force, and maximum displacement convergence were set to $10^{-6} \mathrm{Ha}$, $0.002 \mathrm{Ha} / \AA$, and $0.0005 \AA$, respectively. All calculations were performed using the Gaussian suite code [48], employing the Becke's hybrid three-parameter [49,50] exchange-correlation functional in combination with the Perdew and Wang GGA functional PW91, [51,52]; this combination is known as the B3PW91 exchange-correlation functional. The B3PW91 has been employed in other studies of the reactivity of copper clusters with good performance $[53,54]$. Hybrid functionals, including a portion of Hartree-Fock exchange, have shown a superior performance $[53,55,56]$. We employed the LANL2DZ double- $\zeta$-quality with effective core potential (ECP) [57] and the Ahlrichs-type triple- $\zeta$-quality extendedvalence def2-TZVP basis set [58]. The LANL2DZ basis set is used for transition metals due to its low computational cost [59]. With the aim of refining the optimization and the energies, we used an Ahlrichs-type triple- $\zeta$-quality extended-valence def2-TZVP basis set $[58,60]$ that is more accurate for transition metals [61], despite its considerably higher computational cost [62]. In this study, dispersion corrections were considered through the D3 version of Grimme's dispersion [63] as implemented in the Gaussian code. In a previous work, the effect of the dispersion corrections on the structural and energetic properties of $\mathrm{Be}_{4} \mathrm{~B}_{8}$ and $\mathrm{Be}_{6} \mathrm{~B}_{11}{ }^{-}$clusters was studied, and it was found that the energetic ordering of isomers can change when the dispersion is considered [43,47]. Transition states are discarded through a vibrational analysis, making sure that the reported structures are true energy minima. Calculation of the Gibbs free energy properties of a $\mathrm{Cu}_{13}$ cluster requires an exhaustive and systematic sampling of the free-energy surface with the aim of finding all possible low-energy structures [43,47,64]. Foremost, the search for the global minimum in atomic clusters is a complicated task mainly due to the increase in the degrees of freedom of a molecule with the increase in the number of atoms; as a consequence, the number of local minima increases exponentially with the number of atoms. Moreover, the calculated total energy of the cluster demands a high level of quantum mechanical methodology to produce reliable energies. Despite that, several algorithms coupled with DFT have been employed to search for the lowest energy structures on the potential energy surface of atomic clusters, such as the kick methodology [65-77] and genetic algorithms [43,78-81]. Our computational procedure to elucidate the lowest energy consisted of a hybrid genetic algorithm called GALGOSON [43,47]. GALGOSON employs a multi-step and multi-level search strategy in which optimizations are first performed with the LANL2DZ basis set and, in a second step, energy refinements are made using the def2-TZVP basis set. The generation of the initial population took into account 2D and 3D structures [73,78], with an initial population of 650 random structures for the $\mathrm{Cu}_{13}$ cluster; the algorithm was stopped when the putative global minimum persisted for five generations $[43,47]$. Chemical bonding was examined using the adaptive natural density partitioning (AdNDP) method [47,82]. AdNDP analyzes the first-order reduced density matrix and recovers Lewis bonding (1c-2e or 2c-2e, i.e., lone pairs (LPs), or two-center-two-electron bonds) and delocalized bonding elements (associated with the concept of electron delocalization).

In this study, the fundamental thermodynamic properties such as enthalpy $\mathrm{H}(\mathrm{T})$ and entropy $S(T)$ and Gibbs free energy dependent on temperature were computed within 
the framework of nanothermodynamics $[43,47,83,84]$ through the partition function $Q$ described in refs. $[43,85,86]$ or any standard text relating to thermodynamics $[87,88]$. The total partition function $Q$ is the product of the $\mathrm{q}_{\text {trasn }}, \mathrm{q}_{\mathrm{rot}}, \mathrm{q}_{\mathrm{vib}}$, and $\mathrm{q}_{\text {elec }}[86,89]$ computed under the rigid rotor, harmonic oscillator, Born-Oppenheimer, ideal gas, and particle-in-abox approximations $[43,47]$. The thermal populations $\mathrm{P}(\mathrm{T})$ at absolute temperature $\mathrm{T}$ or the so-called probability of a particular isomer is computed with Equation (1):

$$
P(T)=\frac{e^{-\beta \Delta \mathrm{G}^{K}}}{\sum e^{-\beta \Delta \mathrm{G}^{K}}}
$$

where $\beta=1 / k_{B} T, k_{B}$ is the Boltzmann constant, $T$ is the temperature, and $\Delta \mathrm{G}^{k}$ is the Gibbs free energy of the kth isomer. Equation (1) establishes that the distribution of isomers among energy levels is a function of energy and temperature $[43,86,90]$.

\section{Results and Discussion}

The most important low-energy structures of a neutral $\mathrm{Cu}_{13}$ cluster optimized at the B3PW91-GD3/def2TZVP level of theory found in this study are shown in Figure 1. At room temperature, the isomers depicted in Figure 1a,b contributed to $94 \%$ of the molecular properties in a Boltzmann ensemble; thus, almost all molecular properties were due to those isomers. Additionally, they are chiral structures. The putative chiral global minimum is depicted in Figure 1a with symmetry $C_{1}$. These are bilayered structures composed of a shared pentagonal bipyramid interspersed with a distorted hexagonal ring with a $\mathrm{Cu}$ atom capping one of its faces and two $\mathrm{Cu}$ atoms capping the other face of the hexagonal ring, in good agreement with similar structures [28,91,92]. The pentagonal bipyramid interspersed with the hexagonal ring is built with $12 \mathrm{Cu}$ atoms. One more $\mathrm{Cu}$ atom caps the pentagonal bipyramid; this capping $\mathrm{Cu}$ atom is responsible for the chirality of the $\mathrm{Cu}_{13}$ cluster. Our calculated $\mathrm{Cu}-\mathrm{Cu}$ bond length on the putative chiral global minimum is $2.432 \AA$, in good agreement with other reported DFT calculations of a $\mathrm{Cu}-\mathrm{Cu}$ dimer of $2.248 \AA$ [93] and also with an experimental bond length of 2.22 [94,95], slightly above $5.3 \%$ the experimentally determined value. The calculated vibrational frequency of $\mathrm{Cu}_{13}$ was $60 \mathrm{~cm}^{-1}$, whereas the computed vibrational frequency of the $\mathrm{Cu}-\mathrm{Cu}$ dimer was $245 \mathrm{~cm}^{-1}$, again in good agreement with the experimental value of $265 \mathrm{~cm}^{-1}$ [95]. We also explored the higher multiplicity of quartets and found that the lowest energy structure lay $20.5 \mathrm{kcal} / \mathrm{mol}$ above the doublet putative chiral global minimum energy structure. The second structure that was higher in free energy lay at $0.40 \mathrm{kcal} / \mathrm{mol}$ at room temperature; it was also a bilayered structure, similar to the putative global minimum, but with $C_{2}$ symmetry. Iwasa et al. [96] reported a similar double-layer structure as a putative global minimum with $C_{2}$ symmetry, but without considering the temperature. One of our previous studies showed that these tiny Gibbs free energy differences are derived from rotational entropy [47]. The $C_{1}$ and $C_{2}$ symmetry clusters adopted a hollow layered structure. The following higher energy isomer lay at $1.0 \mathrm{kcal} / \mathrm{mol}$ at room temperature and was an achiral buckled-biplanar (BBP) structure with Cs symmetry, which agrees with previous work [97]. At room temperature, its contributions to the molecular properties were less than $6 \%$. The average bond length on isomer BBP was $2.432 \AA$, similar to the average bond length of the chiral putative global minimum. Next, higher energy structures lay $3.9 \mathrm{kcal} / \mathrm{mol}$ above the chiral putative global minimum, and their average bond length was $2.444 \AA$, slightly larger than the average bond length of $2.432 \AA$ of the putative global minimum. This also appeared as a bilayered chiral structure with a shared hexagonal bipyramid interspersed with a hexagonal bipyramid. The following higher energy structure lay $5.29 \mathrm{kcal} / \mathrm{mol}$ above the putative minimum global. It was a bilayered structure consisting of 12 atoms, with 1 atom capping one of its faces. It is depicted in Figure 1e. Structures located at higher energy than $5.5 \mathrm{kcal} / \mathrm{mol}$ above the putative global minimum are depicted in Figure 1f,g. Those structures also adopted a layered structure with no interior atoms, with similar morphology to that of low-energy isomers. These two 
structures did not contribute to the molecular properties in the studied temperature range. The $\mathrm{Cu}_{13}$ cluster low-energy structures preferentially adopted morphologies of bilayered structures rather than highly symmetric $3 \mathrm{D}$ structures. In contrast, $\mathrm{Au}_{13}$ clusters prefer planar structures due to relativistic effects [36]; therefore, further studies are needed to investigate why bilayered structures in the $\mathrm{Cu}_{13}$ cluster are energetically preferred. For the $\mathrm{Cu}_{13}$ cluster, the icosahedron structure is not energetically favorable in the temperature range examined, which is consistent with previous work where the authors did not consider the temperature [1]. In this study, the icosahedron structure was located at $24.6 \mathrm{kcal} / \mathrm{mol}$ above the putative global minimum at room temperature. To understand the bonding situation in the chiral putative global minimum structure, we performed an AdNDP analysis; the results are shown in Figure 2. This analysis revealed the presence of 5 sets of 13 1c-2e bonds with occupation numbers (ONs) between 1.98 and 1.99 le l, i.e., lone pairs (LPs) corresponding to the fully filled $3 \mathrm{~d}$ shell in each $\mathrm{Cu}$ atom. The bonding in this cluster was then due to the $4 \mathrm{~s}$ shell electrons for which the bonding pattern, as revealed by AdNDP, consisted of 6 sets of 13c-2e completely delocalized bonds, plus a 9c-1e bond corresponding to the unpaired electron which, as shown in Figure 2, was mostly delocalized in the peripheral atoms of the cluster.

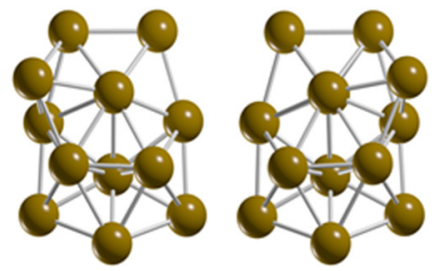

a $(0.0)\left(C_{1}\right)$

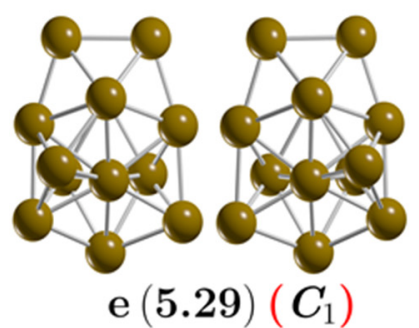

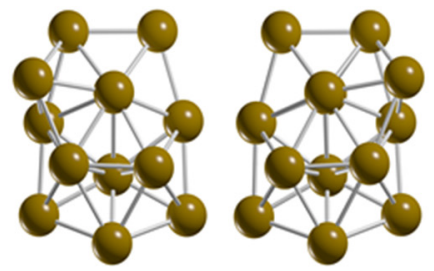

$\mathrm{b}(\mathbf{0 . 4 0})\left(\boldsymbol{C}_{2}\right)$

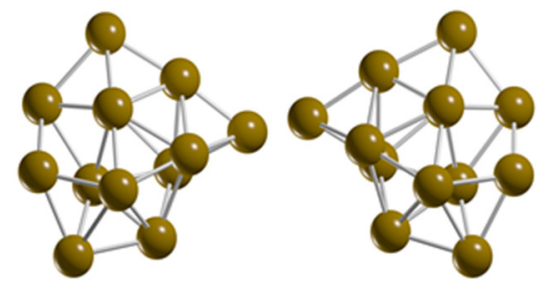

f $(5.58)\left(C_{1}\right)$
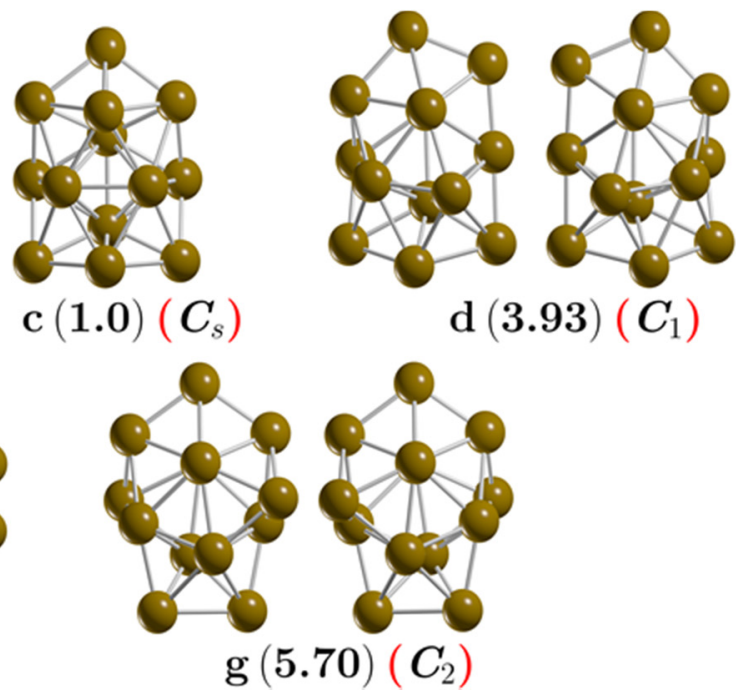

Figure 1. (Color online) The chiral lowest energy structure is depicted in (a), the chiral low-energy structures are depicted in $(\mathbf{b}, \mathbf{d}, \mathbf{e}-\mathbf{g})$ whereas the achiral structure is depicted in (c). Those structures were optimized at the PW91-GD3/def2TZVP level of theory. The first letter indicates the isomer, the relative Gibbs free energies in $\mathrm{kcal} / \mathrm{mol}$ appear in round parentheses computed at $298.15 \mathrm{~K}$, and the point group symmetry in red round parentheses. The isomers, represented in (a,b), differ only in molecular symmetry. The isomer with $\mathrm{C}_{2}$ symmetry has a Gibbs free energy equal to RTln $\sigma$ less than the non-symmetric $\mathrm{C}_{1}$ isomer. The RMSD between the isomer with symmetry $C_{1}$ and the isomer with symmetry $C_{2}$ is 0.0014 . All atomic $X Y Z$ coordinates are given in Supplementary materials. 


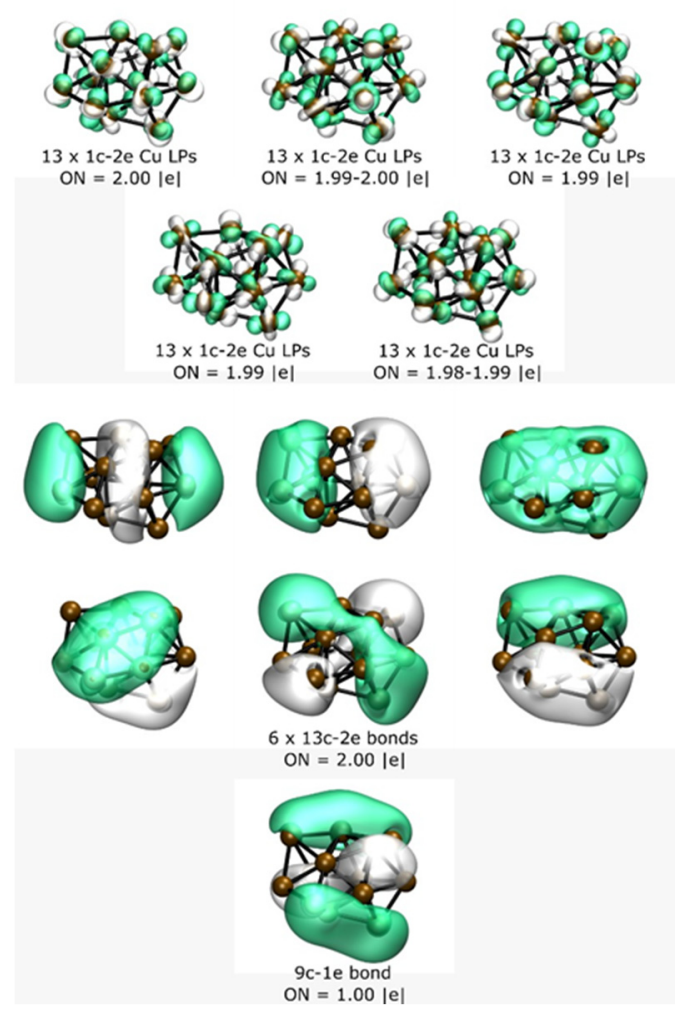

Figure 2. (Color online) Results of the AdNDP analysis of the lowest energy isomer of the $\mathrm{Cu}_{13}$ system.

\section{Energetics}

Temperature drastically affects the Gibbs free energy of the isomers; therefore, in a molecular ensemble (collection), the energetic ordering of isomers changes. Besides, from a theoretical point of view, the energetic ordering can also change when computing energies using different levels of theory $[43,98]$. To gain further insight into the energetic ordering of the low-lying isomers, we optimized the low-lying energy structures employing three more DFT functionals: TPSS, [99] PBE, [100], and BP86 [50] with def2-TZVP [58] basis set. The purpose was to ascertain the origin of the slight $0.41 \mathrm{kcal} / \mathrm{mol}$ differences (below the chemical accuracy of $1 \mathrm{kcal} / \mathrm{mol}$ ) in the relative Gibbs free energy (Table 1) and that these are not due to numerical errors, algorithmic approximations, integration grids, or functional and basis set dependence, to name a few. The relative energies computed at B3PW91-D3/def2-TZVP, TPSS-D3/def2-TZVP, PBE-D3/def2-TZVP, and BP86-D3/def2TZVP are shown in Table 1; Columns third through fifth show electronic energy, electronic with zero-point energy, and Gibbs free energy at 298.15 K at the B3PW91-D3/def2-TZVP level of theory. Columns sixth to ninth show Gibbs free energy at 298.15 K at TPSSD3/def2-TZVP, PBE-D3/def2-TZVP, and BP86-D3/def2-TZVP levels of theory, respectively. A more detailed analysis of the results in Table 1 shows that the relative electronic energy of the four chiral low-energy isomers labeled in Table $1(\mathrm{a}, \mathrm{b}, \mathrm{c}, \mathrm{d})$, with symmetry $\mathrm{C}_{1}$, $\mathrm{C}_{1}, \mathrm{C}_{2}$, and $\mathrm{C}_{2}$, respectively, is zero, considering the $\mathrm{ZPE}$; also, the relative electronic energy is zero. In contrast, the relative Gibbs free energy at $298.15 \mathrm{~K}$ shown in the fifth column is $0.41 \mathrm{kcal} / \mathrm{mol}$. The relative Gibbs free energy at $298.15 \mathrm{~K}$ for the TPSS, PBE, BP86 DFT functions, between the putative global minimum and the second isomer, is also $0.41 \mathrm{kcal} / \mathrm{mol}$. This Gibbs free energy difference does not depend on the functional employed, as shown in Table 1. At temperature $\mathrm{T}=0$, the total energy of an isomer is the electronic energy plus ZPE. If the temperature increases, entropic effects start to play, and Gibbs's free energy determines the global minimum. At any temperature $\mathrm{T}$, the isomers, represented in Figure $1 \mathrm{a}, \mathrm{b}$, differ only in molecular symmetry. The isomer with $C_{2}$ symmetry has a Gibbs free energy equal to RTln $\sigma$ less than the non-symmetric $C_{1}$ isomer. Here $\mathrm{R}$ is the universal gas constant, $\mathrm{T}$ temperature, and $\sigma$ is the symmetry number. 
The symmetry number appears in the denominator of the molecular rotational partition function $[43,47,101,102]$. This implies that the less symmetric isomers at finite temperature are more thermodynamically stable than the more symmetric ones due to the energy factor given by RTln $\sigma$. The factor becomes zero at $\mathrm{T}=0$ and increases linearly with temperature. Figure S1 (Supplementary materials) shows the RTln $\sigma$ factor as a function of temperature and for different symmetry numbers. For our optimized low-energy isomers with $\mathrm{C}_{2}$ symmetry, the symmetry number is 2 , thus, the Gibbs free energy at $298.15 \mathrm{~K}$ with and without symmetry will differ by $0.41 \mathrm{kcal} / \mathrm{mol}$ regardless of the DFT method. This value is higher at high temperatures and with higher symmetry numbers. For example, the benzene molecule with $D_{6 h}$ symmetry has a symmetry number 12 , the Gibbs free energy at $298.15 \mathrm{~K}$ with and without symmetry will differ by $1.47 \mathrm{kcal} / \mathrm{mol}$, which is greater than the chemical precision. Here, we call this the effect of the symmetry number on the Gibbs free energy and on the thermal populations at temperature $\mathrm{T}$; the symmetry number appears when identical atoms are considered indistinguishable and are determined solely by the point group symmetry of the molecule. We emphasize the importance of symmetry in calculating thermal populations at absolute temperature $\mathrm{T}$ or the so-called population probability or relative populations, hence the molecular properties. For example, the melting temperature for a symmetrical molecule is higher than a non-symmetrical molecule; moreover, the activation energy barrier could be higher when we consider a non-symmetrical molecule in the calculation of the transition state. The energy computed at different theoretical levels influences the energy distribution of the isomers and, as a consequence, the Boltzmann weights. For the four DFT functionals used in this study, the energy ordering is preserved, although differences in the energy between the isomers occur; for each DFT functional, the main contributors to any molecular property of $\mathrm{Cu}_{13}$ are always the chiral isomers depicted in Figure 1a.

Table 1. Relative energy in $\mathrm{kcal} / \mathrm{mol}$ of the low-lying isomers depicted in Figure 1 labeled from a to $\mathrm{g}$, employing various density functionals: B3PW91, TPSS, PBE, and BP86, with the def2TZVP basis set. Point group symmetry (Symmetry), electronic energy $\left(\varepsilon_{0}\right)$, electronic energy plus zero-point energy $\left(\varepsilon_{0}+\varepsilon_{\mathrm{ZPE}}\right)$, and Gibbs free energy $(\Delta \mathrm{G})$ computed at room temperature. The tiny values of relative Gibbs free energy $(0.41 \mathrm{kcal} / \mathrm{mol})$ differences among isomers labeled a, b, c, and $\mathrm{d}$ and computed at $298.15 \mathrm{~K}$ are due to the rotational entropy, which depends on the point group symmetry.

\begin{tabular}{|c|c|c|c|c|c|c|c|}
\hline \multirow{3}{*}{$\begin{array}{l}\text { Isomers } \\
\text { Labeling } \\
\text { (Figure 1) }\end{array}$} & \multirow{3}{*}{ Symmetry } & \multicolumn{6}{|c|}{ Functionals } \\
\hline & & \multicolumn{3}{|c|}{ B3PW91 } & \multirow{2}{*}{$\begin{array}{c}\text { TPSS } \\
\Delta \mathrm{G}\end{array}$} & \multirow{2}{*}{$\begin{array}{l}\text { PBE } \\
\Delta G\end{array}$} & \multirow{2}{*}{$\begin{array}{c}\text { BP86 } \\
\Delta \mathrm{G} \\
\end{array}$} \\
\hline & & $\varepsilon_{0}$ & $\varepsilon_{0}+\varepsilon_{\mathrm{ZPE}}$ & $\Delta \mathrm{G}$ & & & \\
\hline $\mathrm{a}$ & $C_{1}$ & 0.0 & 0.0 & 0.0 & 0.0 & 0.0 & 0.0 \\
\hline b & $\mathrm{C}_{1}$ & 0.0 & 0.0 & 0.0 & 0.0 & 0.0 & 0.0 \\
\hline c & $\mathrm{C}_{2}$ & 0.0 & 0.0 & 0.40 & 0.40 & 0.42 & 0.40 \\
\hline d & $\mathrm{C}_{2}$ & 0.0 & 0.0 & 0.41 & 0.41 & 0.42 & 0.41 \\
\hline $\mathrm{e}$ & $C_{s}$ & 0.90 & 0.93 & 1.0 & 0.72 & 0.55 & 0.86 \\
\hline $\mathrm{f}$ & $C_{1}$ & 4.71 & 4.59 & 3.93 & 5.60 & 3.85 & 3.56 \\
\hline g & $\mathrm{C}_{1}$ & 4.71 & 4.59 & 3.94 & 5.60 & 3.85 & 3.56 \\
\hline
\end{tabular}

\section{Enantiomerization Energy of a Pair of Enantiomers of the $\mathrm{Cu}_{13}$ Cluster at Finite Temperature}

The process in which one enantiomer in a pair is converted into the other is known as enantiomerization; enantiomers each have an equal probability of occurrence, and the same energy. The enantiomerization energy or activation energy at temperature $\mathrm{T}$ defines the configurational stability. In certain cases, a low enantiomerization energy is undesirable [103]. Two reaction mechanisms compete for the interconversion from $P$ to $\mathrm{M}$ structures, and the shape of the energy barriers (or IRC) is similar to the inverted double-well potential [104] (see the two videos in Supplementary materials for the intrinsic reaction paths, called route $A$ and route $B$ ). Figure 3 a shows the reaction mechanism for the interconversion between $\mathrm{P}$ and $\mathrm{M}$ structures for route $\mathrm{A}$, which proceeds via a two-step 
mechanism consisting of two symmetric steps with only one intermediate. Figure 3a depicts the transition states TS1 and TS2, the intermediate (Int), and the putative lowest energy pair of enantiomers P and M. The energy of enantiomerization was $12.15 \mathrm{kcal} / \mathrm{mol}$, whereas the activation energy for the interconversion of the intermediate to $\mathrm{P} / \mathrm{M}$ structures was $5 \mathrm{kcal} / \mathrm{mol}$ at room temperature. The intermediate state was located at $7.13 \mathrm{kcal} / \mathrm{mol}$ above the putative chiral lowest energy structure. The structures of the TS1 and TS2 states are depicted in Figure 3a. They appeared to be bilayer structures composed of a shared pentagonal bipyramid interspersed with a distorted hexagonal ring. The green atom represents the $\mathrm{Cu}$ atom that caps one edge of the pentagonal bipyramid and is responsible for the chirality of the $\mathrm{Cu}_{13}$ cluster. The intermediate state structure for the same bilayer presented $12 \mathrm{Cu}$ atoms and the green $\mathrm{Cu}$ atom caps one of the faces in the pentagonal bipyramid. Figure $3 b$ shows the enantiomerization energy $E_{a e}$ depicted by a solid blue line. The relative energy of the intermediate, $E_{I n t}$, for the putative global chiral structures is depicted by a solid red line. As the temperature increased, the enantiomerization energy increased almost linearly. In contrast, the relative energy of the intermediate with respect to the putative global minimum decreased linearly, implying that the inverted double-wall became energetically greater. The activation energy for the interconversion between the intermediate and the $\mathrm{M}$ structure was $5 \mathrm{kcal} / \mathrm{mol}$ at room temperature; this increased linearly, from $4 \mathrm{kcal} / \mathrm{mol}$ at a temperature of $100 \mathrm{~K}$ to $9.5 \mathrm{kcal} / \mathrm{mol}$ at a temperature of $1200 \mathrm{~K}$. As a consequence, the probability of interconversion from $\mathrm{P}$ to $\mathrm{M}$ decreased as the temperature increased. In contrast, at low temperatures, the enantiomerization energy trend reached a minimum, whereas the relative energy of the intermediate increased; thus, the energy activation for the interconversion of the intermediate to the $\mathrm{P} / \mathrm{M}$ states tended to be smaller. These results suggest that at high temperatures, the enantiomerization barrier energy increased, and the intermediate state energy became more significant, stabilizing chirality and allowing the separation of enantiomers at room temperature [46]. To elucidate the behavior of the interconversion from $\mathrm{P}$ to $\mathrm{M}$ structures; We computed the reaction rate constants based on Equation (2) (Eyring equation) that used the activation barrier $\Delta \mathrm{G}$ between the putative global minimum $\mathrm{P} / \mathrm{M}$ structures and the transition state and did not consider the tunneling effect. The Eyring equation relates the rate constant to temperature and the activation free energy.

$$
k=k_{0} \frac{K_{B} T}{h} e^{\frac{-\Delta \mathrm{G}}{\mathrm{RT}}}
$$

In Equation (2), $k$ is the rate constant, $k_{0}$ transmission coefficient that in the absence of other kinetic data is set to $1, K_{B}$ is Boltzmann constant, $\mathrm{T}$ is the temperature, $h$ is the Planck constant, $\mathrm{R}$ is ideal gas constant, and $\Delta \mathrm{G}$ is the activation energy barrier. We consider the rate-determining step in the overall reaction is the rate of interconversion between $\mathrm{P} / \mathrm{M}$ and intermediary structures, and it is the slowest step; besides, its high activation energy characterizes it. (The activation energy barrier $\Delta \mathrm{G}$ is computed with the statistical thermodynamics). The height of the activation energy barrier at room temperature for interconversion between $\mathrm{P} / \mathrm{M}$ and intermediary structures in route $\mathrm{A}$ is $12.14 \mathrm{kcal} / \mathrm{mol}$, which leads to a rate constant of $7.84 \times 10^{3} 1 / \mathrm{s}$, whereas the activation energy barrier at $900 \mathrm{~K}$ is $14.0 \mathrm{kcal} / \mathrm{mol}$, which leads to a rate constant of $7.47 \times 10^{9} 1 / \mathrm{s}$. This show that the rate constant increases at high temperatures, and it agrees with the thermal populations where the contribution of all isomers is less than $10 \%$ at high temperatures. We also have to consider that the melting point for copper is $1358 \mathrm{~K}$, thus around this temperature, the glass state will dominate. Regarding dispersion, if it is not considered, the energy barriers tend to increase. For ease of comparison, Table 2 shows the values of the two similar reaction mechanisms A and B, taking into account the D3 dispersion of Grimme. Energetically, the reaction mechanism of route $B$ is not considerably different from that of route $A$, as we can see in Table 2. 

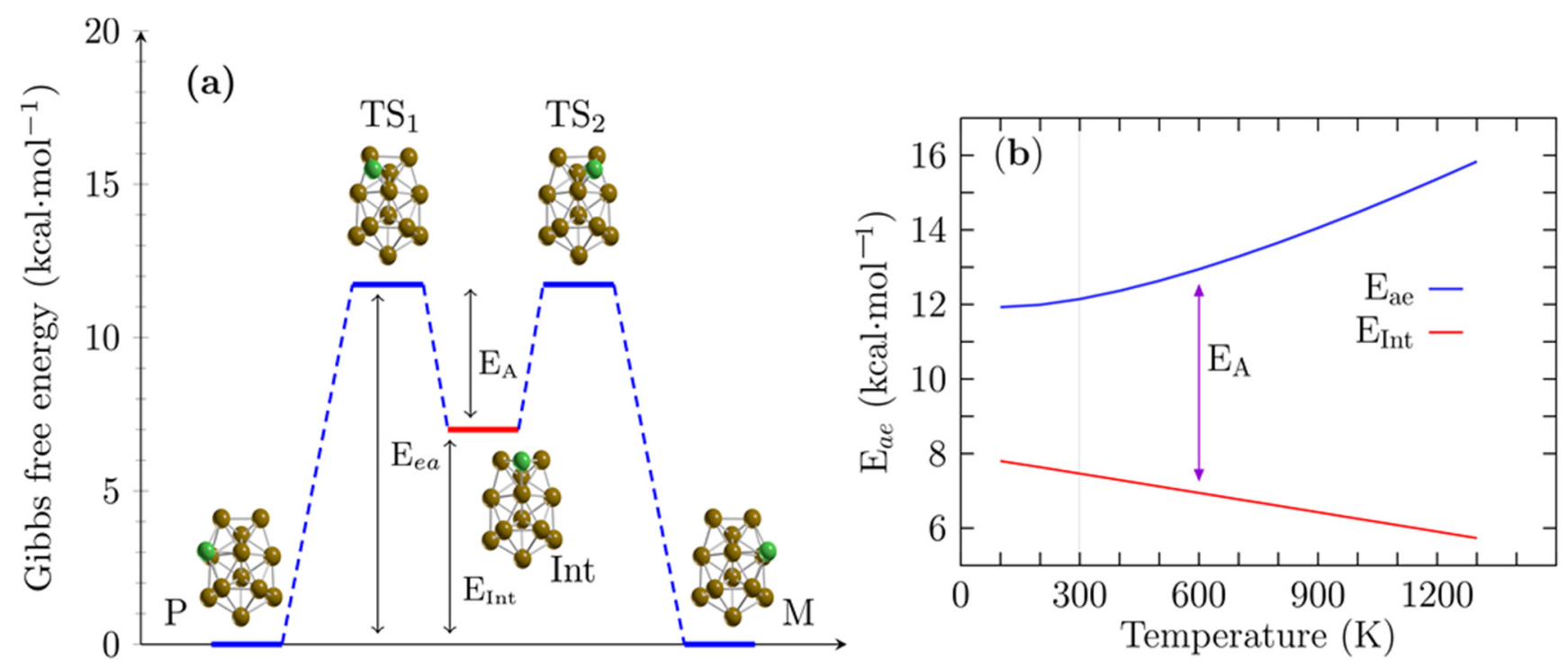

Figure 3. (Color online) (a) shows the energy profile of a chemical reaction (route A) with two symmetric transition states (TS1, TS2) and one intermediate (Int) for the interconversion between the lowest energy $\mathrm{P}$ and $\mathrm{M}$ enantiomers (see video of intrinsic reaction path in Supplementary materials). The enantiomerization energy ( $\mathrm{E}_{\mathrm{ea}}$ ) was $12.14 \mathrm{kcal} / \mathrm{mol}$ at room temperature. In contrast, the intermediate structure lay at $7.13 \mathrm{kcal} / \mathrm{mol}\left(\mathrm{E}_{\text {Int }}\right)$ above the putative global minimum $\mathrm{P}$ and $\mathrm{M}$ structures; thus, the activation energy in the interconversion from the intermediate (Int) to the $\mathrm{M}$ or $\mathrm{P}$ structure was 5.0 $\mathrm{kcal} / \mathrm{mol}$, at room temperature. $(b)$ displays the enantiomerization energy $\left(\mathrm{E}_{\mathrm{ea}}\right)$ depicted by a blue-solid line. The relative energy of the intermediate structure $\left(E_{\text {Int }}\right)$ with respect to the putative global minimum is depicted by a red solid line. The activation energy barrier (EA) between the intermediate structure and the $\mathrm{P}$ or $\mathrm{M}$ structure is indicated by the violet arrow and is the difference between $\mathrm{E}_{\mathrm{ea}}$ and $\mathrm{E}_{\mathrm{Int}}$ for temperatures ranging from 100 to $1300 \mathrm{~K}$. The green and copper-colored spheres represent the copper atoms. Green represents a $\mathrm{Cu}$ atom that is moving; the chirality is due to this atom.

Table 2. Values of enantiomerization energy $\left(E_{e a}\right)$, relative energy of the intermediate $\left(E_{I n t}\right)$, and activation energy $\left(\mathrm{E}_{\mathrm{A}}\right)$ for two reaction mechanisms, $\mathrm{A}$ and $\mathrm{B}$, taking or not considering D3 Grimme's dispersion. The inclusion of dispersion lowers the energy barriers, i.e., in $\mathrm{B}$ the $\mathrm{E}_{\mathrm{A}}$ decreased by $7 \%$ (from 4.3 to $4.0 \mathrm{kcal} / \mathrm{mol}$ ).

\begin{tabular}{ccccccc}
\hline & \multicolumn{3}{c}{ Route $\mathbf{A}$} & \multicolumn{3}{c}{ Route $\mathbf{B}$} \\
Level of Theory & $\mathbf{E}_{\text {ea }}$ & $\mathbf{E}_{\text {int }}$ & $\mathbf{E}_{\mathbf{A}}$ & $\mathbf{E}_{\text {ea }}$ & $\mathbf{E}_{\text {int }}$ & $\mathbf{E}_{\mathbf{A}}$ \\
\hline B3PW91-D3/def2TZVP & 12.2 & 7.1 & 5.0 & 14.8 & 10.8 & 4.0 \\
B3PW91/def2TZVP & 12.3 & 6.4 & 6.0 & 15.6 & 10.3 & 4.3 \\
\hline
\end{tabular}

The $\mathrm{E}_{\mathrm{A}}$ between the intermediate and the $\mathrm{P}$ or $\mathrm{M}$ structure for route $\mathrm{A}$ and taking D3 Grimme's dispersion into account was $5.0 \mathrm{kcal} / \mathrm{mol}$, as we can see in the first line of Table 2, whereas the $\mathrm{E}_{\mathrm{A}}$ for route $\mathrm{B}$ was $4 \mathrm{kcal} / \mathrm{mol}$. In contrast, the values of $\mathrm{E}_{\mathrm{A}} \mathrm{s}$ computed without dispersion for both routes $A$ and $B$, in the second line of Table 1, were 5.97 and $4.28 \mathrm{kcal} / \mathrm{mol}$, respectively. Based on these results, the effect of the dispersion was to lower the energy barriers in the interconversion of the chiral $\mathrm{Cu}_{13}$ cluster. Moreover, the reaction mechanism with the highest probability to occur was route A, because it had lower energy barriers than route B. Figure S2 shows the energy profile of a chemical reaction with two symmetric transition states (TS1, TS2) and one intermediate (Int) for the interconversion between the lowest energy $\mathrm{P}$ and $\mathrm{M}$ enantiomers for route $\mathrm{B}$, and for ease comparison, the Figure $\mathrm{S} 2$ shows the energy profile of a chemical reaction for route A.

\section{Relative Population of $\mathrm{Cu}_{13}$ Cluster at Finite Temperature}

In chemistry, physics, and biology, the lowest energy structure and all the low-energy structures near the global minimum are crucial because all molecular properties are statisti- 
cal averages derived from the ensemble of molecular conformations [43]. The probability of occurrence of each particular isomer is depicted in Figure 4 for the $\mathrm{Cu}_{13}$ cluster. It was determined by employing Equation (1) and temperatures ranging from 20 to $1500 \mathrm{~K}$ at the B3PW91-D3/def2TZVP level of theory. Figure 4 shows the probability of occurrence considering all chiral and achiral structures. The analysis of these results led to an interesting observation. The pair of enantiomers that appeared as the putative global minimum at temperature $0 \mathrm{~K}$ was strongly dominant in the temperature range from 20 to $1500 \mathrm{~K}$. Moreover, there were no solid-solid transformation points in any temperature ranges, which means no interchange of dominant low-energy structures at high temperatures. A closer inspection of Figure 4 shows that the decay of probability of occurrence of the pair of enantiomers with symmetry $C_{1}$, depicted by a red solid line, is closer to linear rather than exponential for temperatures ranging from 20 to $600 \mathrm{~K}$. Above $600 \mathrm{~K}$ and up to $1500 \mathrm{~K}$, the decay is exponential. At $300 \mathrm{~K}$, the chiral structure has a probability of $32 \%$, whereas the second isomer located $0.4 \mathrm{kcal} / \mathrm{mol}$ above the putative global minimum has a probability of $16 \%$. The above discussion shows that all molecular properties of the $\mathrm{Cu}_{13}$ cluster are attributed to the chiral putative global minimum. The probability of occurrence of chiral isomers is shown in Figure 1b, located at $0.41 \mathrm{kcal} / \mathrm{mol}$ above the putative global minimum and depicted by blue and yellow solid lines in Figure 4 . The probability of occurrence for structures with $C_{1}$ and $C_{2}$ symmetries showed similar behaviors but different values; however, the molecular properties are attributed to only one pair of enantiomers with symmetry $C_{1}$. The probability of occurrence for the achiral structure, which is shown in Figure $1 \mathrm{c}$, located $1 \mathrm{kcal} / \mathrm{mol}$ above the putative global minimum, is depicted by a green solid line in Figure 4; it started to increase around a temperature of $120 \mathrm{~K}$, and at room temperature, it is has a probability of $5 \%$. At $700 \mathrm{~K}$, the highest probability of occurrence was reached, corresponding to $12 \%$; above this temperature, up to $1500 \mathrm{~K}$, it started to decrease. Note that above $800 \mathrm{~K}$ and up to $1200 \mathrm{~K}$, the achiral structure with $\mathrm{C}_{\mathrm{s}}$ symmetry and the putative global minimum structures with $C_{2}$ symmetries coexisted. The Boltzmann ensemble was composed of an equal mixture of $\mathrm{M}$ and $\mathrm{P}$ enantiomers; thus, the chiral properties were null in all ranges of temperature, i.e., the $\mathrm{Cu}_{13}$ cluster did not exhibit properties such as vibrational/electronic circular dichroism. In ranging temperatures from 1200 to $1500 \mathrm{~K}$, all isomers coexist with less than ten percent probability. To wit, all isomers are equally populated for hot temperatures or when the temperature increases to large values. The bulk melting temperature of copper, $1358 \mathrm{~K}$ [105]; thus, we must consider that the anharmonic effects become strong at high temperatures [43]. From the thermal population, we consider the entropic-temperature term has a small effect on the $\mathrm{Cu}_{13}$ cluster distribution of isomers on the scale of temperature, as shown in Figure 4. 


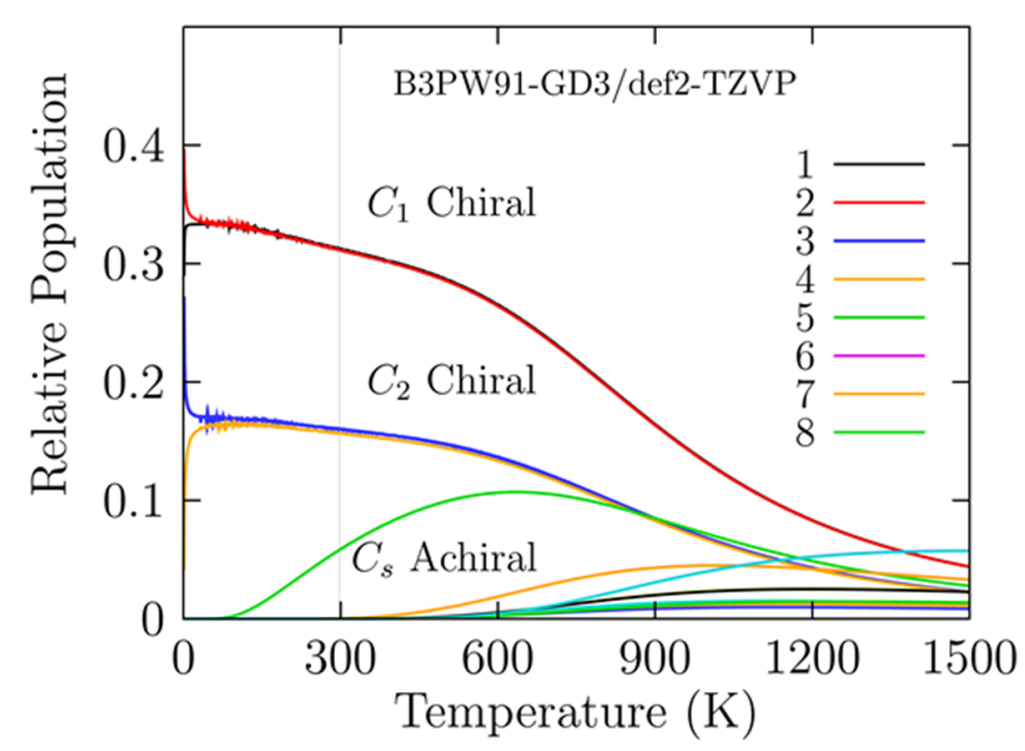

Figure 4. (Color online) Probability of occurrence for all isomers at temperatures ranging from 20 to $1500 \mathrm{~K}$. The red and black solid lines depict the probability occurrence of the putative chiral global minimum with symmetry $C_{1}$ and strongly dominate in all ranges of temperatures. The bulk melting temperature of copper is $1358 \mathrm{~K}$ [105]; thus, our results below this temperature are consistent. Probability of occurrence or thermal population computed with DFT functionals: TPSS, PBE, and BP86 are displayed in Figure S3.

\section{Conclusions}

We explored the potential and free energy surface of the neutral $\mathrm{Cu}_{13}$ cluster with an efficient cascade-type algorithm coupled to DFT. We found that the putative global minimum was a pair of enantiomers that strongly dominated at room temperature. Our findings show that the chirality exhibited by the $\mathrm{Cu}_{13}$ cluster emerged from the $\mathrm{Cu}$ atom capping a face of the core $\mathrm{Cu}_{12}$ cluster. We showed that for the interconversion between $\mathrm{P}$ and $\mathrm{M}$ structures, two similar reaction mechanisms were possible. Both of them closed in their energy barriers and proceeded via two symmetric steps. The energy of enantiomerization and the energy barrier between the intermediate and the $\mathrm{P} / \mathrm{M}$ structures increased as the temperature increased. We computed the reaction rate constants based on the Eyring equation; our findings show that, at high temperatures, enantiomerization is favored. The entropic-temperature term did not significantly influence the energy barriers; thus, they are mainly composed of enthalpic energy. Regarding Grimme's dispersion D3, this lowers the energy barriers, i.e., in route B, the EA decreased by $7 \%$ (from 4.3 to $4.0 \mathrm{kcal} / \mathrm{mol}$ ). We showed that the pair of enantiomers with $C_{1}$ symmetries strongly dominated at room temperature revealed by the thermal population. Hence, at body temperature, all the molecular properties were attributable to those structures. For each DFT functional (B3PW91, TPSS, PBE, and BP86) used in this study, the thermal population and energetic ordering of the isomers are preserved, although differences in the energy between the isomers occur; the main contributors to any molecular property of $\mathrm{Cu}_{13}$ are always the chiral isomers. The bonding in the lowest energy chiral $\mathrm{Cu}_{13}$ cluster is due to the $4 \mathrm{~s}$ shell electrons for which the bonding pattern, as revealed by AdNDP, consisted of 6 sets of 13c-2e completely delocalized bonds, plus a $9 \mathrm{c}-1 \mathrm{e}$ bond corresponding to the unpaired electron. Future work will focus on the computation of UV-vis absorption of the Cu clusters employing Boltzmann weighted spectra, comparing it with a single UV spectrum of the putative global minimum. 
Supplementary Materials: The following is available online, Figure S1: (Color online) shows the RTln $\sigma$ factor as a function of temperature and for different symmetry numbers. For our optimized low-energy isomers with $C_{2}$ symmetry, the symmetry number is 2; thus, the Gibbs free energy at $298.15 \mathrm{~K}$ with and without symmetry will differ by $0.41 \mathrm{kcal} / \mathrm{mol}$ regardless of the DFT method, Figure S2a: (Color online) Figure (a) shows the energy profile of a chemical reaction (route A) with two symmetric transition states (TS1, TS2) and one intermediate (Int) for the interconversion between the lowest energy P and M enantiomers, Figure S2b: (Color online) Figure (a) shows the energy profile of a chemical reaction (route B) with two symmetric transition states (TS1, TS2) and one intermediate (Int) for the interconversion be-tween the lowest energy P and M enantiomers, Figure S3: (Color online) Probability of occurrence or thermal population for all isomers at temperatures ranging from 20 to 1500 K computed with DFT functionals: (a) B3PW91; (b) TPSS; (c) PBE; (d) BP86. The influence of functional over the thermal population is not significant. The red and black solid lines depict the probability occurrence of the putative chiral global minimum with symmetry $\mathrm{C}_{1}$ and strongly dominate at room temperature. The bulk melting temperature of copper is $1358 \mathrm{~K}$; thus, our results below this temperature are consistent and describe correctly the $\mathrm{Cu}_{13}$ system. Video S1: $\mathrm{Cu}_{13}$ route A, Video $\mathrm{S} 2: \mathrm{Cu}_{13}$ route $\mathrm{B}$.

Author Contributions: C.E.B.-G.: methodology, software, validation, performed the calculations, drafted, and wrote the manuscript; E.R.-C.: methodology, software, validation, performed the calculations and drafted the manuscript; E.P.-S.: methodology, software, validation, performed the calculations and drafted the manuscript; J.M.Q.-C.: methodology, software, validation, performed the calculations, and drafted the manuscript; E.Z.-G.: validation, performed the calculations; T.d.C.-C.: methodology, validation, performed the calculations, and drafted the manuscript; G.M.-G.: performed the calculations, analysis, and drafted the manuscript; C.C.-Q. performed the calculations, analysis, resources, and drafted the manuscript and revised and wrote the manuscript; A.d.-L.-F.: performed the calculations, analysis, and drafted the manuscript; M.F.M.-d.-C.-S.: performed the calculations, analysis, and drafted the manuscript; M.C.-V.: performed the calculations, analysis, and drafted the manuscript; F.O.-C.: software development, performed calculations, analysis, and drafted the manuscript; T.G.: software development, performed calculations, analysis, and drafted the manuscript; S.J.C.: software development, performed calculations, analysis, and drafted the manuscript; A.V.-E.: software development, design and validation, performed calculations and analysis, drafted the manuscript, and performed the data analyses, AdNDP; S.P.: performed calculations and analysis, drafted the manuscript, performed the data analyses, investigation, and revised and wrote the manuscript; J.L.C.: conception of the study, software development, design and validation, performed calculations and analysis, drafted the manuscript, performed the data analyses, investigation, resources, and revised and wrote the manuscript. All authors have read and agreed to the published version of the manuscript.

Funding: This research received no external funding.

Institutional Review Board Statement: Not applicable.

Informed Consent Statement: Not applicable.

Data Availability Statement: Data are contained within the article.

Acknowledgments: C.E.B.-G. thanks Conacyt for a scholarship (860052). E.P.-S. thanks Conacyt for a scholarship (1008864). E.R.-C. thanks Conacyt for a scholarship (1075701). We are grateful to Carmen Heras and L.C.C. Daniel Mendoza for granting us access to their clusters and computational support. Computational resources for this work were provided by the High-Performance Computing Area of the University of Sonora. We are also grateful to the computational chemistry laboratory for providing computational resources, ELBAKYAN, and PAKAL supercomputers. Powered@NLHPC: this research was partially supported by the supercomputing infrastructure of the NLHPC (ECM-02).

Conflicts of Interest: The authors declare no conflict of interest.

Sample Availability: Samples of the compounds are not available from the authors. 


\section{References}

1. Chaves, A.S.; Piotrowski, M.J.; Da Silva, J.L.F. Evolution of the structural, energetic, and electronic properties of the 3d, 4d, and $5 \mathrm{~d}$ transition-metal clusters (30 TMn systems for $n=2-15$ ): A density functional theory investigation. Phys. Chem. Chem. Phys. 2017, 19, 15484-15502. [CrossRef]

2. Chen, W.; Chen, S. Oxygen Electroreduction Catalyzed by Gold Nanoclusters: Strong Core Size Effects. Angew. Chem. Int. Ed. 2009, 48, 4386-4389. [CrossRef]

3. Henry, C.R. Surface studies of supported model catalysts. Surf. Sci. Rep. 1998, 31, 231-325. [CrossRef]

4. Santiago González, B.; Rodríguez, M.J.; Blanco, C.; Rivas, J.; López-Quintela, M.A.; Martinho, J.M.G. One Step Synthesis of the Smallest Photoluminescent and Paramagnetic PVP-Protected Gold Atomic Clusters. Nano Lett. 2010, 10, 4217-4221. [CrossRef] [PubMed]

5. Barnes, W.L.; Dereux, A.; Ebbesen, T.W. Surface plasmon subwavelength optics. Nature 2003, 424, 824-830. [CrossRef] [PubMed]

6. Cathcart, N.; Kitaev, V. Silver Nanoclusters: Single-Stage Scaleable Synthesis of Monodisperse Species and Their Chirooptical Properties. J. Phys. Chem. C 2010, 114, 16010-16017. [CrossRef]

7. Ding, X.L.; Xue, W.; Ma, Y.P.; Wang, Z.C.; He, S.G. Density functional study on cage and noncage $\left(\mathrm{Fe}_{2} \mathrm{O}_{3}\right)_{n}$ clusters. J. Chem. Phys. 2009, 130, 014303. [CrossRef] [PubMed]

8. Majid, A.; Zahid, S.; Khan, S.U.D.; Khan, S.U.D. Theoretical study of (TM)FeO $3(\mathrm{TM}=3 \mathrm{~d}$ transition metals) molecular clusters. J. Nanoparticle Res. 2020, 22, 145. [CrossRef]

9. Zhang, J.; Liu, J.; Peng, Q.; Wang, X.; Li, Y. Nearly Monodisperse $\mathrm{Cu}_{2} \mathrm{O}$ and $\mathrm{CuO}$ Nanospheres: Preparation and Applications for Sensitive Gas Sensors. Chem. Mater. 2006, 18, 867-871. [CrossRef]

10. Gawande, M.B.; Goswami, A.; Felpin, F.X.; Asefa, T.; Huang, X.; Silva, R.; Zou, X.; Zboril, R.; Varma, R.S. Cu and Cu-Based Nanoparticles: Synthesis and Applications in Catalysis. Chem. Rev. 2016, 116, 3722-3811. [CrossRef] [PubMed]

11. Lu, Y.; Chen, W. Sub-nanometre sized metal clusters: From synthetic challenges to the unique property discoveries. Chem. Soc. Rev. 2012, 41, 3594-3623. [CrossRef]

12. Wang, Z.; Chen, B.; Rogach, A.L. Synthesis, optical properties and applications of light-emitting copper nanoclusters. Nanoscale Horiz. 2017, 2, 135-146. [CrossRef] [PubMed]

13. Lin, Y.S.; Lin, Y.F.; Nain, A.; Huang, Y.F.; Chang, H.T. A critical review of copper nanoclusters for monitoring of water quality. Sens. Actuators Rep. 2021, 3, 100026. [CrossRef]

14. Itoh, M.; Kumar, V.; Adschiri, T.; Kawazoe, Y. Comprehensive study of sodium, copper, and silver clusters over a wide range of sizes $2 \leq N \leq 75$. J. Chem. Phys. 2009, 131, 174510. [CrossRef]

15. Jug, K.; Zimmermann, B.; Calaminici, P.; Köster, A.M. Structure and stability of small copper clusters. J. Chem. Phys. 2002, 116, 4497-4507. [CrossRef]

16. Calaminici, P.; Janetzko, F.; Koster, A.M.; Mejia-Olvera, R.; Zuniga-Gutierrez, B. Density functional theory optimized basis sets for gradient corrected functionals: 3d transition metal systems. J. Chem. Phys. 2007, 126, 044108. [CrossRef] [PubMed]

17. Massobrio, C.; Pasquarello, A.; Dal Corso, A. Structural and electronic properties of small $\mathrm{Cu}_{n}$ cluster using generalized-gradient approximations within density functional theory. J. Chem. Phys. 1998, 109, 6626-6630. [CrossRef]

18. Calaminici, P.; Koster, A.M.; Russo, N.; Salahub, D.R. A density functional study of small copper clusters: Cu $\mathrm{Cu}_{n}(n<5)$. J. Chem. Phys. 1996, 105, 9546-9556. [CrossRef]

19. Poater, A.; Duran, M.; Jaque, P.; Toro-Labbé, A.; Sola, M. Molecular Structure and Bonding of Copper Cluster Monocarbonyls $\mathrm{Cu}_{n} \mathrm{CO}(n=1-9)$. J. Chem. Phys. B 2006, 110, 6526-6536. [CrossRef] [PubMed]

20. Calaminici, P.; Koster, A.M.; Gómez-Sandoval, Z. Density Functional Study of the Structure and Properties of $\mathrm{Cu}_{9}$ and $\mathrm{Cu}_{9}^{-} \cdot J$. Chem. Theory Comput. 2007, 3, 905-913. [CrossRef] [PubMed]

21. Yang, M.; Yang, F.; Jackson, K.A.; Jellinek, J. Probing the structural evolution of $\mathrm{Cu}_{N}{ }^{-}, N=9-20$, through a comparison of computed electron removal energies and experimental photoelectron spectra. J. Chem. Phys. 2010, 132, 064306. [CrossRef]

22. Lecoultre, S.; Rydlo, A.; Félix, C.; Buttet, J.; Gilb, S.; Harbich, W. Optical absorption of small copper clusters in neon: Cu $n$, $(n=1-9)$. J. Chem. Phys. 2011, 134, 074303. [CrossRef]

23. Binns, C. Nanoclusters deposited on surfaces. Surface Sci. Rep. 2001, 44, 1-49. [CrossRef]

24. Brack, M. The physics of simple metal clusters: Self-consistent jellium model and semiclassical approaches. Rev. Mod. Phys. 1993, 65, 677-732. [CrossRef]

25. Martin, T. Shells of atoms. Phys. Rep. 1996, 273, 199-241. [CrossRef]

26. Sakurai, M.; Watanabe, K.; Sumiyama, K.; Suzuki, K. Magic numbers in transition metal (Fe, Ti, Zr, Nb, and Ta) clusters observed by time-of-flight mass spectrometry. J. Chem. Phys. 1999, 111, 235-238. [CrossRef]

27. Darby, S.; Mortimer-Jones, T.V.; Johnston, R.L.; Roberts, C. Theoretical study of $\mathrm{Cu}-\mathrm{Au}$ nanoalloy clusters using a genetic algorithm. J. Chem. Phys. 2002, 116, 1536-1550. [CrossRef]

28. Guvelioglu, G.H.; Ma, P.; He, X.; Forrey, R.C.; Cheng, H. Evolution of Small Copper Clusters and Dissociative Chemisorption of Hydrogen. Phys. Rev. Lett. 2005, 94, 026103. [CrossRef] [PubMed]

29. Itoh, M.; Kumar, V.; Kawazoe, Y. Growth Behaviors And Electronic Structures Of Na And Cu Nanoclusters: The Role Of Sp-D Hybridization. Int. J. Mod. Phys. B 2005, 19, 2421-2426. [CrossRef]

30. Yang, M.; Jackson, K.A.; Koehler, C.; Frauenheim, T.; Jellinek, J. Structure and shape variations in intermediate-size copper clusters. J. Chem. Phys. 2006, 124, 024308. [CrossRef] 
31. Jiang, M.; Zeng, Q.; Zhang, T.; Yang, M.; Jackson, K.A. Icosahedral to double-icosahedral shape transition of copper clusters. J. Chem. Phys. 2012, 136, 104501. [CrossRef] [PubMed]

32. Zhang, R.; Peng, M.; Duan, T.; Wang, B. Insight into size dependence of $C_{2}$ oxygenate synthesis from syngas on Cu cluster: The effect of cluster size on the selectivity. Appl. Surf. Sci. 2017, 407, 282-296. [CrossRef]

33. Shuangjing, C.; Xin, C.; Hui, Z. Probing the activity of $\mathrm{Ni}_{13}, \mathrm{Cu}_{13}$, and $\mathrm{Ni}_{12} \mathrm{Cu}$ clusters towards the ammonia decomposition reaction by density functional theory. J. Mater. Sci. 2017, 52, 3162-3168. [CrossRef]

34. Takahashi, K. First-Principles Design of $\mathrm{Cu}_{12}$ shell Fe core Core-Shell Clusters Assembled with $\mathrm{K}_{3} \mathrm{O}$ into Hexameric Rings: Implications for Gas-Storage Materials. ACS Appl. Nano Mater. 2020, 3, 55-58. [CrossRef]

35. Deng, Y.J.; Tian, N.; Zhou, Z.Y.; Huang, R.; Liu, Z.L.; Xiao, J.; Sun, S.G. Alloy tetrahexahedral Pd-Pt catalysts: Enhancing significantly the catalytic activity by synergy effect of high-index facets and electronic structure. Chem. Sci. 2012, 3, 1157-1161. [CrossRef]

36. Chou, J.P.; Hsing, C.R.; Wei, C.M.; Cheng, C.; Chang, C.M. Ab initio random structure search for 13-atom clusters of FCC elements. J. Phys. Condens. Matter 2013, 25, 125305. [CrossRef]

37. Akola, J.; Häkkinen, H.; Manninen, M. Ionization potential of aluminum clusters. Phys. Rev. B 1998, 58, 3601-3604. [CrossRef]

38. Ebeling, D.; Šekutor, M.; Stiefermann, M.; Tschakert, J.; Dah, J.E.P.; Carlson, R.M.K.; Schirmeisen, A.; Schreiner, P.R. Assigning the absolute configuration of single aliphatic molecules by visual inspection. Nat. Commun. 2018, 9, 2420. [CrossRef]

39. Li, W.L.; Zhao, Y.F.; Hu, H.S.; Li, J.; Wang, L.S. A Quasiplanar Chiral Boron Cluster. Angew. Chem. Int. Ed. 2014, 53, 5540-5545. [CrossRef]

40. Barroso, J.; Cabellos, J.L.; Pan, S.; Murillo, F.; Zarate, X.; Fernandez-Herrera, M.A.; Merino, G. Revisiting the racemization mechanism of helicenes. Chem. Commun. 2018, 54, 188-191. [CrossRef]

41. Lv, P.; Lu, Z.; Yang, F.; Zhang, Y.; Yang, X.; Xu, G.; Yang, Z. A theoretical study of the lowest-energy PtPd co-doped silicon clusters: Chirality and fluxional transformation. Phys. Lett. A 2017, 381, 873-878. [CrossRef]

42. Kong, Y.J.; Yan, Z.P.; Li, S.; Su, H.F.; Li, K.; Zheng, Y.X.; Zang, S.Q. Photoresponsive Propeller-like Chiral AIE Copper(I) Clusters. Angew. Chem. Int. Ed. 2020, 59, 5336-5340. [CrossRef]

43. Buelna-Garcia, C.E.; Cabellos, J.L.; Quiroz-Castillo, J.M.; Martinez-Guajardo, G.; Castillo-Quevedo, C.; de Leon-Flores, A.; Anzueto-Sanchez, G.; Martin-del Campo-Solis, M.F. Exploration of Free Energy Surface and Thermal Effects on Relative Population and Infrared Spectrum of the $\mathrm{Be}_{6} \mathrm{~B}_{11}{ }^{-}$Fluxional Cluster. Materials 2021, 14, 112. [CrossRef]

44. Rao, Y.; Lei, Y.; Cui, X.; Liu, Z.; Chen, F. Optical and magnetic properties of Cu-doped 13-atom Ag nanoclusters. J. Alloy. Compd. 2013, 565, 50-55. [CrossRef]

45. Baletto, F.; Ferrando, R. Structural properties of nanoclusters: Energetic, thermodynamic, and kinetic effects. Rev. Mod. Phys. 2005, 77, 371-423. [CrossRef]

46. Yang, W.; Longhi, G.; Abbate, S.; Lucotti, A.; Tommasini, M.; Villani, C.; Catalano, V.J.; Lykhin, A.O.; Varganov, S.A.; Chalifoux, W.A. Chiral Peropyrene: Synthesis, Structure, and Properties. J. Am. Chem. Soc. 2017, 139, 13102-13109. [CrossRef] [PubMed]

47. Buelna-Garcia, C.E.; Robles-Chaparro, E.; Parra-Arellano, T.; Quiroz-Castillo, J.M.; del Castillo-Castro, T.; Martínez-Guajardo, G.; Castillo-Quevedo, C.; de León-Flores, A.; Anzueto-Sánchez, G.; Martin-del Campo-Solis, M.F.; et al. Theoretical Prediction of Structures, Vibrational Circular Dichroism, and Infrared Spectra of Chiral $\mathrm{Be}_{4} \mathrm{~B}_{8}$ Cluster at Different Temperatures. Molecules 2021, 26, 3953. [CrossRef] [PubMed]

48. Frisch, M.J.; Trucks, G.W.; Schlegel, H.B.; Scuseria, G.E.; Robb, M.A.; Cheeseman, J.R.; Scalmani, G.; Barone, V.; Mennucci, B.; Petersson, G.A.; et al. Gaussian 09 Revision D; Gaussian Inc.: Wallingford, CT, USA, 2009. [CrossRef]

49. Becke, A.D. Density-functional thermochemistry. III. The role of exact exchange. J. Chem. Phys. 1993, 98, 5648-5652. [CrossRef]

50. Becke, A.D. Density-functional exchange-energy approximation with correct asymptotic behavior. Phys. Rev. A 1988, 38, 3098-3100. [CrossRef] [PubMed]

51. Perdew, J.P.; Wang, Y. Accurate and simple analytic representation of the electron-gas correlation energy. Phys. Rev. B 1992, 45, 13244-13249. [CrossRef]

52. Perdew, J.P.; Chevary, J.A.; Vosko, S.H.; Jackson, K.A.; Pederson, M.R.; Singh, D.J.; Fiolhais, C. Atoms, molecules, solids, and surfaces: Applications of the generalized gradient approximation for exchange and correlation. Phys. Rev. B 1992, 46, 6671-6687. [CrossRef]

53. Fernández, E.; Boronat, M.; Corma, A. Trends in the Reactivity of Molecular $\mathrm{O}_{2}$ with Copper Clusters: Influence of Size and Shape. J. Phys. Chem. C 2015, 119, 19832-19846. [CrossRef]

54. Jaque, P.; Toro-Labbé, A. Characterization of copper clusters through the use of density functional theory reactivity descriptors. J. Chem. Phys. 2002, 117, 3208-3218. [CrossRef]

55. Cramer, C.J.; Truhlar, D.G. Density functional theory for transition metals and transition metal chemistry. Phys. Chem. Chem. Phys. 2009, 11, 10757-10816. [CrossRef]

56. Cohen, A.J.; Mori-Sánchez, P.; Yang, W. Challenges for Density Functional Theory. Chem. Rev. 2012, 112, 289-320. [CrossRef] [PubMed]

57. Hay, P.J.; Wadt, W.R. Ab initio effective core potentials for molecular calculations. Potentials for K to Au including the outermost core orbitals. J. Chem. Phys. 1985, 82, 299-310. [CrossRef]

58. Weigend, F.; Ahlrichs, R. Balanced basis sets of split valence, triple zeta valence and quadruple zeta valence quality for $H$ to Rn: Design and assessment of accuracy. Phys. Chem. Chem. Phys. 2005, 7, 3297-3305. [CrossRef] 
59. Hay, P.J.; Wadt, W.R. Ab initio effective core potentials for molecular calculations. Potentials for the transition metal atoms Sc to Hg. J. Chem. Phys. 1985, 82, 270-283. [CrossRef]

60. Zeng, Q.; Wang, X.; Yang, M.L.; Fu, H.B. Interplay between geometrical and electronic stability of neutral and anionic $\mathrm{Cu}_{13}$ clusters: A first-principles study. Eur. Phys. J. D 2010, 58, 125-129. [CrossRef]

61. Bardakc, T.; Kumru, M.; Altun, A. Molecular structures, charge distributions, and vibrational analyses of the tetracoordinate $\mathrm{Cu}(\mathrm{II}), \mathrm{Zn}(\mathrm{II}), \mathrm{Cd}(\mathrm{II})$, and $\mathrm{Hg}(\mathrm{II})$ bromide complexes of $p$-toluidine investigated by density functional theory in comparison with experiments. J. Mol. Struct. 2016, 1116, 292-302. [CrossRef]

62. Matczak, P. Assessment of B3LYP combined with various ECP basis sets for systems containing Pd, Sn, and Pb. Comput. Theor. Chem. 2012, 983, 25-30. [CrossRef]

63. Grimme, S.; Antony, J.; Ehrlich, S.; Krieg, H. A consistent and accurate ab initio parametrization of density functional dispersion correction (DFT-D) for the 94 elements H-Pu. J. Chem. Phys. 2010, 132, 154104. [CrossRef] [PubMed]

64. Heiles, S.; Johnston, R.L. Global optimization of clusters using electronic structure methods. Int. J. Quantum Chem. 2013, 113, 2091-2109. [CrossRef]

65. Vargas-Caamal, A.; Cabellos, J.L.; Ortiz-Chi, F.; Rzepa, H.S.; Restrepo, A.; Merino, G. How Many Water Molecules Does it Take to Dissociate HCl? Chem. A Eur. J. 2016, 22, 2812-2818. [CrossRef] [PubMed]

66. Ravell, E.; Jalife, S.; Barroso, J.; Orozco-Ic, M.; Hernández-Juárez, G.; Ortiz-Chi, F.; Pan, S.; Cabellos, J.L.; Merino, G. Structure and Bonding in $\mathrm{CE}_{5}{ }^{-}(\mathrm{E}=\mathrm{Al}-\mathrm{Tl})$ Clusters: Planar Tetracoordinate Carbon versus Pentacoordinate Carbon. Chem. Asian J. 2018, 13, 1467-1473. [CrossRef]

67. Pan, S.; Moreno, D.; Cabellos, J.L.; Romero, J.; Reyes, A.; Merino, G.; Chattaraj, P.K. In Quest of Strong Be-Ng Bonds among the Neutral Ng-Be Complexes. J. Phys. Chem. A 2014, 118, 487-494. [CrossRef] [PubMed]

68. Cui, Z.H.; Ding, Y.H.; Cabellos, J.L.; Osorio, E.; Islas, R.; Restrepo, A.; Merino, G. Planar tetracoordinate carbons with a double bond in $\mathrm{CAl}_{3}$ E clusters. Phys. Chem. Chem. Phys. 2015, 17, 8769-8775. [CrossRef]

69. Vargas-Caamal, A.; Pan, S.; Ortiz-Chi, F.; Cabellos, J.L.; Boto, R.A.; Contreras-Garcia, J.; Restrepo, A.; Chattaraj, P.K.; Merino, G. How strong are the metallocene-metallocene interactions? Cases of ferrocene, ruthenocene, and osmocene. Phys. Chem. Chem. Phys. 2016, 18, 550-556. [CrossRef]

70. Cui, Z.H.; Vassilev-Galindo, V.; Luis Cabellos, J.; Osorio, E.; Orozco, M.; Pan, S.; Ding, Y.h.; Merino, G. Planar pentacoordinate carbon atoms embedded in a metallocene framework. Chem. Commun. 2017, 53, 138-141. [CrossRef]

71. Vargas-Caamal, A.; Ortiz-Chi, F.; Moreno, D.; Restrepo, A.; Merino, G.; Cabellos, J.L. The rich and complex potential energy surface of the ethanol dimer. Theor. Chem. Acc. 2015, 134, 16. [CrossRef]

72. Florez, E.; Acelas, N.; Ibarguen, C.; Mondal, S.; Cabellos, J.L.; Merino, G.; Restrepo, A. Microsolvation of $\mathrm{NO}_{3}{ }^{-}$: Structural exploration and bonding analysis. RSC Adv. 2016, 6, 71913-71923. [CrossRef]

73. Grande-Aztatzi, R.; Martinez-Alanis, P.R.; Cabellos, J.L.; Osorio, E.; Martínez, A.; Merino, G. Structural evolution of small gold clusters doped by one and two boron atoms. J. Comput. Chem. 2014, 35, 2288-2296. [CrossRef] [PubMed]

74. Elena Navarro, R.; Serna-Medina, O.; Soberanes, Y.; Cabellos, J.L.; Inoue, M.; Santacruz, H.; Álvaro Posada-Amarillas. ${ }^{1}$ H NMR of paramagnetic $\mathrm{Dy}^{3+}$ complex with DTPA-amide $p$-xylylene-cyclophane; possible probing action toward D-histidine and histamine. Polyhedron 2020, 181, 114474. [CrossRef]

75. Barroso, J.; Mondal, S.; Cabellos, J.L.; Osorio, E.; Pan, S.; Merino, G. Structure and Bonding of Alkali-Metal Pentalenides. Organometallics 2017, 36, 310-317. [CrossRef]

76. Hadad, C.Z.; Florez, E.; Merino, G.; Cabellos, J.L.; Ferraro, F.; Restrepo, A. Potential Energy Surfaces of WC 6 Clusters in Different Spin States. J. Phys. Chem. A 2014, 118, 5762-5768. [CrossRef] [PubMed]

77. Contreras, M.; Pan, S.; Orozco-Ic, M.; Cabellos, J.L.; Merino, G. $\mathrm{E}_{3} \mathrm{M}_{3}{ }^{+}(\mathrm{E}=\mathrm{C}-\mathrm{Pb}, \mathrm{M}=\mathrm{Li}-\mathrm{Cs})$ Clusters: The Smallest Molecular Stars. Chem. Eur. J. 2017, 23, 11430-11436. [CrossRef]

78. Dong, X.; Jalife, S.; Vásquez-Espinal, A.; Ravell, E.; Pan, S.; Cabellos, J.L.; Liang, W.y.; Cui, Z.h.; Merino, G. Li $2 B_{12}$ and Li $B_{12}$ : Prediction of the Smallest Tubular and Cage-like Boron Structures. Angew. Chem. Int. Ed. 2018, 57, 4627-4631. [CrossRef]

79. Guo, J.C.; Feng, L.Y.; Wang, Y.J.; Jalife, S.; Vásquez-Espinal, A.; Cabellos, J.L.; Pan, S.; Merino, G.; Zhai, H.J. Coaxial Triple-Layered versus Helical $\mathrm{Be}_{6} \mathrm{~B}_{11}-$ Clusters: Dual Structural Fluxionality and Multifold Aromaticity. Angew. Chem. Int. Ed. 2017, 56, 10174-10177. [CrossRef]

80. Dong, X.; Jalife, S.; Vásquez-Espinal, A.; Barroso, J.; Orozco-Ic, M.; Ravell, E.; Cabellos, J.L.; Liang, W.y.; Cui, Z.h.; Merino, G. $\mathrm{Li}_{2} \mathrm{~B}_{24}$ : The simplest combination for a three-ring boron tube. Nanoscale 2019, 11, 2143-2147. [CrossRef] [PubMed]

81. Alexandrova, A.N.; Boldyrev, A.I. Search for the $\mathrm{Li}_{n} 0 /+1 /-1(n=5-7)$ Lowest-Energy Structures Using the ab Initio Gradient Embedded Genetic Algorithm (GEGA). Elucidation of the Chemical Bonding in the Lithium Clusters. J. Chem. Theory Comput. 2005, 1, 566-580. [CrossRef] [PubMed]

82. Zubarev, D.Y.; Boldyrev, A.I. Developing paradigms of chemical bonding: Adaptive natural density partitioning. Phys. Chem. Chem. Phys. 2008, 10, 5207-5217. [CrossRef] [PubMed]

83. Li, Z.H.; Truhlar, D.G. Nanothermodynamics of metal nanoparticles. Chem. Sci. 2014, 5, 2605-2624. [CrossRef]

84. Li, Z.H.; Jasper, A.W.; Truhlar, D.G. Structures, Rugged Energetic Landscapes, and Nanothermodynamics of $\mathrm{Al}_{n}(2 \leq n \leq 65)$ Particles. J. Am. Chem. Soc. 2007, 129, 14899-14910. [CrossRef] [PubMed]

85. Grimme, S. Supramolecular Binding Thermodynamics by Dispersion-Corrected Density Functional Theory. Chem. Eur. J. 2012, 18, 9955-9964. [CrossRef] 
86. Dzib, E.; Cabellos, J.L.; Ortíz-Chi, F.; Pan, S.; Galano, A.; Merino, G. Eyringpy: A program for computing rate constants in the gas phase and in solution. Int. J. Quantum Chem. 2019, 119, e25686. [CrossRef]

87. McQuarrie, D.A.M. Statistical Mechanics; Chemistry Series; Harper \& Row: Manhattan, NY, USA, 1975.

88. Hill, T. An Introduction to Statistical Thermodynamics; Addison-Wesley Series in Chemistry; Dover Publications: Mineola, NY, USA, 1986.

89. Pracht, P.; Grimme, S. Calculation of absolute molecular entropies and heat capacities made simple. Chem. Sci. 2021, 12, 6551-6568. [CrossRef] [PubMed]

90. Mendoza-Wilson, A.M.; Balandrán-Quintana, R.R.; Cabellos, J.L. Thermochemical behavior of sorghum procyanidin trimers with $\mathrm{C} 4-\mathrm{C} 8$ and $\mathrm{C} 4-\mathrm{C} 6$ interflavan bonds in the reaction with superoxide anion radical and $\mathrm{H}_{2} \mathrm{O}_{2}$-forming $\mathrm{NADH}$-oxidase flavoenzyme. Comput. Theor. Chem. 2020, 1186, 112912. [CrossRef]

91. Rodriguez-Kessler, P.L.; Rodriguez-Dominguez, A.R.; Muñoz Castro, A. Systematic cluster growth: A structure search method for transition metal clusters. Phys. Chem. Chem. Phys. 2021, 23, 4935-4943. [CrossRef]

92. Limbu, D.K.; Madueke, M.U.; Atta-Fynn, R.; Drabold, D.A.; Biswas, P. Ab initio density-functional studies of 13-atom Cu and Ag clusters. J. Phys. Conf. Ser. 2019, 1252, 012009. [CrossRef]

93. Guvelioglu, G.H.; Ma, P.; He, X.; Forrey, R.C.; Cheng, H. First principles studies on the growth of small Cu clusters and the dissociative chemisorption of $\mathrm{H}_{2}$. Phys. Rev. B 2006, 73, 155436. [CrossRef]

94. Kabir, M.; Mookerjee, A.; Bhattacharya, A. Copper clusters: Electronic effect dominates over geometric effect. Eur. Phys. J. D At. Mol. Opt. Plasma Phys. 2004, 31, 477-485. [CrossRef]

95. Pauling, L. On the nature of the bonding in $\mathrm{Cu}_{2}-\mathrm{A}$ Comment. J. Chem. Phys. 1983, 78, 3346. [CrossRef]

96. Iwasa, T.; Sato, T.; Takagi, M.; Gao, M.; Lyalin, A.; Kobayashi, M.; Shimizu, K.i.; Maeda, S.; Taketsugu, T. Combined Automated Reaction Pathway Searches and Sparse Modeling Analysis for Catalytic Properties of Lowest Energy Twins of Cu $\mathrm{u}_{13}$. J. Phys. Chem. A 2019, 123, 210-217. [CrossRef]

97. Longo, R.C.; Gallego, L.J. Structures of 13-atom clusters of FCC transition metals by ab initio and semiempirical calculations. Phys. Rev. B 2006, 74, 193409. [CrossRef]

98. De la Puente, E.; Aguado, A.; Ayuela, A.; López, J.M. Structural and electronic properties of small neutral (MgO) $n$ clusters. Phys. Rev. B 1997, 56, 7607-7614. [CrossRef]

99. Tao, J.; Perdew, J.P.; Staroverov, V.N.; Scuseria, G.E. Climbing the Density Functional Ladder: Nonempirical Meta-Generalized Gradient Approximation Designed for Molecules and Solids. Phys. Rev. Lett. 2003, 91, 146401. [CrossRef] [PubMed]

100. Perdew, J.P.; Burke, K.; Ernzerhof, M. Generalized Gradient Approximation Made Simple. Phys. Rev. Lett. 1996, 77, 3865-3868. [CrossRef] [PubMed]

101. Fernández-Ramos, A.; Ellingson, B.A.; Meana-Pañeda, R.; Marques, J.M.C.; Truhlar, D.G. Symmetry numbers and chemical reaction rates. Theor. Chem. Acc. 2007, 118, 813-826. [CrossRef]

102. Gilson, M.K.; Irikura, K.K. Symmetry Numbers for Rigid, Flexible, and Fluxional Molecules: Theory and Applications. J. Phys. Chem. B 2010, 114, 16304-16317. [CrossRef]

103. Ravat, P. Carbo[n] helicenes Restricted to Enantiomerize: An Insight into the Design Process of Configurationally Stable Functional Chiral PAHs. Chem. A Eur. J. 2021, 27, 3957-3967. [CrossRef]

104. Jensen, B. Quantum Mechanics on Surfaces. In Some Applications of Quantum Mechanics; Pahlavani, M.R., Ed.; IntechOpen: Rijeka, Croatia, 2012. [CrossRef]

105. Grigoryan, V.G.; Springborg, M. Temperature and isomeric effects in nanoclusters. Phys. Chem. Chem. Phys. 2019, 21, 5646-5654. [CrossRef] [PubMed] 